\title{
New anticoagulants for the prevention and treatment of venous thromboembolism
}

\author{
Simon J McRae \\ Jeffrey S Ginsberg
}

Department of Medicine, McMaster University, Hamilton, ON, Canada
Correspondence: Simon J McRae McMaster University Medical Centre HSC 3WII, I 200 Main St West,

Hamilton, ON, Canada, L8N $3 Z 5$

Tel + I $90552 \mid 2100$ ext 73928

Fax + I $90552 \mid 4997$

Email smcrae@mcmaster.ca

\begin{abstract}
Anticoagulant therapy is effective at preventing the development of venous thromboembolism in high-risk patients, and reduces morbidity and mortality in individuals with established thromboembolic disease. Vitamin K antagonists and heparins are currently the most commonly used anticoagulant drugs, but they have practical limitations. Therefore, new antithrombotic agents with predictable dose-responses (thereby decreasing the need for monitoring without compromising efficacy or safety), ideally available in an oral formulation and with a rapidly reversible anticoagulant effect, are needed. New drugs fulfilling some of the above criteria have been developed and have proven to be effective agents for the treatment and prevention of venous thromboembolism.
\end{abstract}

Keywords: venous thromboembolism, anticoagulants, antithrombotic

\section{Introduction}

Venous thromboembolism (VTE), consisting of deep vein thrombosis (DVT) and pulmonary embolism (PE), is a common and potentially fatal disease with an annual incidence of $0.1 \%$ in Caucasian populations (White 2003). Effective antithrombotic therapy has been shown to reduce mortality in patients with PE (Barritt and Jordan 1960) and to reduce extension and recurrence in patients with proximal or distal DVT (Lagerstedt et al 1985; Hull et al 1986). Antithrombotic agents have also been shown to reduce the risk of VTE in a wide variety of high-risk situations, although, despite prophylaxis, the incidence of venous thrombosis is still high in some circumstances such as following major orthopedic surgery (Geerts et al 2001). Despite the proven efficacy of currently available anticoagulants in most situations, limitations of the same drugs continue to complicate their practical use in real life. This has driven the search for new antithrombotic agents that maintain (or improve) efficacy and safety, but that are more convenient to use.

The balance between normal hemostasis and thrombosis is determined by the interaction of numerous individual pro- and anticoagulant factors, increased knowledge of which has enabled identification of novel therapeutic targets (Figure 1). Tissue factor is the trigger initiating normal hemostasis, but if excessive amounts are released, it can also cause venous and arterial thrombosis (Davie 1995). During the initiation stage of coagulation, tissue factor in the presence of calcium binds to activated factor VII (FVIIa) to form the extrinsic tenase complex, which activates FX and FIX. By itself, the initially produced FXa bound to phospholipid converts small amounts of prothrombin to thrombin inefficiently (Mann et al 2003), with the thrombin produced then feeding back to activate FV, FVIII, and FXI, and also initiating platelet activation. This allows formation of intrinsic tenase and prothrombinase complexes on the surface of activated platelets, with the cofactors FVa and FVIIIa optimizing the interaction of the enzyme complexes with their target proteins, resulting 


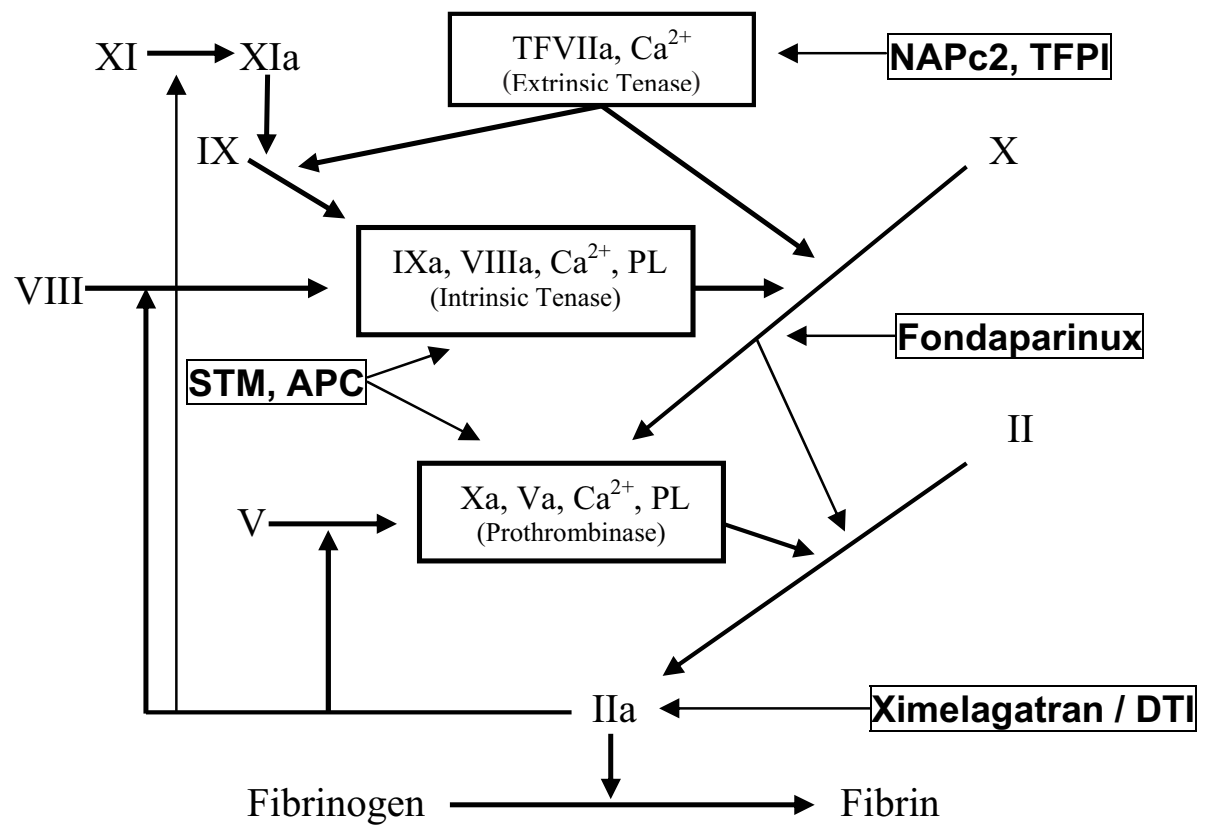

Figure I The coagulation cascade and sites of action of new drugs. Abbreviations: APC, activated protein C; DTI, direct thrombin inhibitors; PL, phospholipids; STM, soluble thrombomodulin;TFPI, tissue factor pathway inhibitor.

in highly efficient activation of FX and prothrombin, respectively. Rapid production of thrombin and clot formation then result (Mann et al 2003).

This explosive process is kept in check by a number of regulatory processes. The initiation phase is kept in check by the stoichiometric inhibitor, tissue factor pathway inhibitor (TFPI). This forms a quaternary complex with FX, FVIIa, and tissue factor leading to their inactivation (Baugh et al 1998). Thrombin also limits its own activation by binding to thrombomodulin on the endothelial cell surface. This limits its procoagulant activity and changes its substrate specificity to the natural anticoagulant, protein $\mathrm{C}$ (Esmon 1989). In combination with its cofactor, protein $S$, activated protein $\mathrm{C}$ inactivates $\mathrm{FVa}$ and FVIIIa, thereby attenuating thrombin production.

Heparin and vitamin $\mathrm{K}$ antagonists, such as warfarin, have long been the main weapons in the antithrombotic armamentarium. Discovered in 1916, unfractionated heparin (UFH) exerts its antithrombotic effect by binding to the natural inhibitor antithrombin (AT), inducing a conformational change that accelerates the rate at which AT inactivates multiple coagulation enzymes (FIXa, FXa, IIa) (Hirsh, Warkentin, et al 2001). UFH requires parenteral administration, and due to variable non-specific binding to plasma proteins, produces a variable anticoagulant response. This non-specific protein binding also results in unwanted side effects such as osteoporosis and heparin-induced thrombocytopenia (HIT), a rare idiosyncratic prothrombotic state due to the production of antiheparin antibodies (Hirsh, Warkentin, et al 2001). Low molecular weight heparin (LMWH) has more predictable pharmacokinetic properties, and has largely replaced UFH for many indications. However, LMWH still can cause HIT and, like UFH, has the theoretical disadvantage of being unable to inactivate thrombin bound to fibrin (Weitz and Crowther 2002).

Warfarin is the most widely used vitamin $\mathrm{K}$ antagonist drug. Like UFH, it targets multiple steps in the coagulation cascade, inhibiting the production of FII (prothrombin), FVII, FIX, and FX (Hirsh, Dalen, et al 2001) Although warfarin is convenient because it is orally administered, it has an unpredictable anticoagulant effect and therefore requires blood monitoring. It has a slow onset and offset of action, and therefore requires the use of vitamin $\mathrm{K}$ and/or plasma products in the event of bleeding (Hirsh, Dalen, et al 2001).

Thus, all currently available anticoagulants have limitations, and there is "room for improvement". Characteristics of the ideal anticoagulant agent include: (1) a predictable anticoagulant effect; (2) a wide therapeutic window (reducing the risk of bleeding and removing the need for monitoring); (3) a rapid onset of action; (4) a rapid offset of action and an available antidote; (5) oral formulation; and (6) once or twice daily dosing (Hirsh et al 2005). In the last 10 years, numerous novel anticoagulant 
agents targeting specific steps in the coagulation pathway (Figure 1) have been developed in an attempt to meet some (or all) of the above criteria. It had been hoped that by targeting specific rather than multiple steps, the risk of bleeding associated with anticoagulant therapy might be minimized, without compromising antithrombotic efficacy. In this article, we will review new anticoagulant agents that have the potential to be used for the prevention or treatment of VTE, and will focus on the two drugs that have been most extensively evaluated for these indications fondaparinux and ximelagatran.

\section{New anticoagulant agents Inhibitors of FVII/tissue factor initiation of coagulation \\ NAPc2}

Nematode anticoagulant protein c2 (NAPc2) is an 85-amino acid protein with anticoagulant properties (Lee and Vlasuk 2003). Initially isolated from the hookworm, it has been produced in a recombinant form, rNAPc2. Both the natural and recombinant forms bind to a non-catalytic site on factor $\mathrm{X}$ or Xa. NAPc2 bound to FXa then forms a quaternary inhibitory complex with TF/FVIIa (Lee and Vlasuk 2003). The ability to bind to FX results in NAPc2 having a prolonged half-life of 50 hours.

In an open-label dose-ranging study, rNAPc2 has been evaluated for prevention of VTE in patients undergoing elective knee arthroplasty (Lee et al 2001). Administered by subcutaneous injection every second day, an rNAPc2 dose of $3 \mu / \mathrm{kg}$ starting 1 hour after surgery was found to be optimal and was associated with an overall rate of deep vein thrombosis of $12.2 \%$. Further trials of NAPc2 for this indication have not been reported.

\section{Indirect factor $\mathrm{Xa}$ inhibitors}

\section{Fondaparinux}

Fondaparinux is a synthetic analogue of the critical pentasaccharide sequence required for binding heparin molecules to AT (Choay et al 1981; Walenga et al 1997). A product of chemical engineering, it has minor modifications from the naturally occurring pentasaccharide moiety, improving the stability of the molecule and resulting in enhanced binding to AT (Walenga et al 1997). Unlike UFH and LMWH, it is a homogeneous product, and because it is not derived from animal sources, there is no concern about viral contamination.

\section{Mechanism of action}

In plasma, fondaparinux binds noncovalently (and therefore reversibly) to its specific target molecule, AT, with 1:1 stoichiometry (Bauer 2003). The interaction with fondaparinux results in a conformational change in the AT molecule (Olson et al 1992) exposing the arginine containing loop responsible for AT binding to factor Xa (Huntington et al 2000). The improved affinity of AT for factor Xa when bound to fondaparinux results in a 300 -fold increase in the Xa inhibitory effect of AT (Olson et al 1992). Once AT binds factor Xa, fondaparinux is released due to a further conformational change, allowing binding to other AT molecules (Bauer 2003). Unlike other heparins, fondaparinux is too short to provide the bridging between AT and thrombin required to catalyze AT mediated inhibition of thrombin (Olson et al 1992).

Although fondaparinux does not directly influence AT mediated inhibition of thrombin, it does inhibit thrombin generation when the coagulation cascade is triggered by tissue factor (Beguin et al 1989; Lormeau and Herault 1993) (Figure 1). The degree of inhibition of thrombin generation has been shown to correlate directly with plasma antifactor Xa activity (Lormeau and Herault 1995). As factor Xa is protected from inhibition by AT-fondaparinux when bound to factor $\mathrm{V}$ and phospholipid as part of the prothrombinase complex (Beguin et al 1989; Brufatto et al 2003), the target is likely to be free factor Xa prior to incorporation. In contrast to unfractionated heparin, fondaparinux inhibits thrombin generation in platelet-rich plasma (Beguin et al 1989; Gerotziafas et al 2004a), presumably because, unlike other heparins, it does not demonstrate non-specific binding to other plasma proteins, in particular platelet factor 4 (PF4) (Bauer 2003; Gerotziafas et al 2004a).

The antithrombotic activity of fondaparinux has been studied in animal models of venous thrombosis, and it was found to be as effective as UFH and LMWH at inhibiting thrombus formation and propagation (Herbert et al 1997; Walenga et al 1997). The antithrombotic effect appears to correlate closely with ex vivo antifactor Xa activity (Carrie et al 1994). In three different animal models, bleeding was not significantly increased in doses far exceeding “therapeutic" levels (Herbert et al 1997; Walenga et al 1997).

\section{Pharmacological considerations}

Given subcutaneously, fondaparinux demonstrates $100 \%$ bioavailability with peak plasma concentrations occurring 1.7 hours after dosing (Donat et al 2002). The drug half-life 
in young healthy volunteers was found to be 17 hours making once daily dosing feasible, and was independent of the initial dose given. Steady state is obtained after the third or fourth once daily dose with a 1.3-fold increase in peak concentration and AUC (Donat et al 2002). The kidney is the major route of clearance, with approximately $70 \%$ of the initial dose recovered in the urine in an unchanged form (Donat et al 2002). Peak plasma concentrations and AUC are linearly correlated with dose and show minimal intersubject variability, obviating the need for monitoring drug levels when renal function is normal (Boneu et al 1995). Patients with reduced creatinine clearance, such as the elderly, show higher peak drug levels and longer drug halflife and may require dose adjustment (Boneu et al 1995; Donat et al 2002).

Fondaparinux does not undergo hepatic metabolism, or interact with other drugs that do so, and no pharmacodynamic or pharmacokinetic interactions were seen with warfarin, piroxicam, aspirin, or digoxin (Bauer 2003). Although there is no data from administration to pregnant human subjects, no evidence of placental transfer was seen in a dually perfused human cotyledon with therapeutic plasma concentrations (Lagrange et al 2002).

\section{Monitoring}

Routine monitoring of fondaparinux is not required. However, estimation of antithrombotic activity may be necessary when patients receiving treatment require urgent invasive intervention. Fondaparinux does not prolong the activated partial thromboplastin time (aPTT), activated clotting time (ACT), or prothrombin time (PT), even in high doses (Boneu et al 1995; Linkins et al 2002). Direct measurement of antifactor Xa levels is therefore required. Variability in results using different antifactor Xa assays calibrated with different LMWH standards emphasizes the need for a standardized assay using a fondaparinux reference preparation (Depasse et al 2004).

\section{Clinical trials}

\section{Prophylaxis trials}

The efficacy and safety of fondaparinux for both the prevention and treatment of VTE have been studied in a number of large clinical trials. An initial dose-finding study of fondaparinux for VTE prophylaxis in patients undergoing total hip replacement (THR) was performed using confirmed clinical or asymptomatic VTE and major bleeding as end points. A clear dose effect on both efficacy and safety was demonstrated, and a dose of $2.5 \mathrm{mg}$ daily, commencing 6 hours after surgery, was identified as the probable optimal dose regimen and was chosen for further evaluation in large phase III trials (Turpie et al 2001).

Four multicentre, double-blind, randomized trials comparing the efficacy and safety of fondaparinux with enoxaparin in major orthopedic surgery have been performed (Bauer et al 2001; Lassen et al 2002; Turpie et al 2002a; Eriksson and Lassen 2003) (Table 1). The EPHESUS (Lassen et al 2002) and PENTATHLON 2000 (Turpie et al 2002a) trials enrolled patients undergoing elective THR; the PENTHIFRA trial involved patients undergoing surgery for hip fracture (Eriksson et al 2001); and PENTAMAKS trial participants underwent elective knee replacement surgery (TKR) (Bauer et al 2001). All trials used the fondaparinux

Table I Prophylactic trials of fondaparinux in major orthopedic surgery

\begin{tabular}{|c|c|c|c|c|c|c|c|c|c|}
\hline \multirow[b]{2}{*}{ Trial } & \multirow{2}{*}{$\begin{array}{r}\text { Control arm dose } \\
\text { of enoxaparin }\end{array}$} & \multicolumn{2}{|c|}{$\begin{array}{r}\text { Fondaparinux } \\
\text { rate of VTE }\end{array}$} & \multicolumn{2}{|c|}{$\begin{array}{l}\text { Control arm } \\
\text { rate of VTE }\end{array}$} & \multicolumn{2}{|c|}{$\begin{array}{r}\text { Fondaparinux } \\
\text { major bleeding }\end{array}$} & \multicolumn{2}{|c|}{$\begin{array}{r}\text { Enoxaparin } \\
\text { major bleeding }\end{array}$} \\
\hline & & $\mathbf{n}$ & $\%$ & $\mathbf{n}$ & $\%$ & $\mathbf{n}$ & $\%$ & $\mathbf{n}$ & $\%$ \\
\hline \multicolumn{10}{|l|}{ Primary trials } \\
\hline EPHESUS & $40 \mathrm{mg} \mathrm{od}{ }^{\mathrm{a}}$ & $37 / 908$ & $4.1^{c}$ & $85 / 919$ & 9.2 & $47 / 1140$ & 4.1 & $32 / 1133$ & 2.8 \\
\hline PENTATHLON & $30 \mathrm{mg}$ bid $^{\mathrm{b}}$ & $48 / 787$ & 6.1 & $66 / 797$ & 8.3 & $20 / 1128$ & 1.8 & $11 / 1129$ & 1.0 \\
\hline PENTHIFRA & $40 \mathrm{mg} \mathrm{od}^{\mathrm{a}}$ & $52 / 626$ & $8.3^{d}$ & $119 / 624$ & 19.1 & $|8 / 83|$ & 2.2 & $19 / 842$ & 2.3 \\
\hline PENTAMAKS & $30 \mathrm{mg}$ bid $^{\mathrm{b}}$ & $45 / 361$ & $12.5^{d}$ & $101 / 363$ & 27.8 & $11 / 517$ & $2.1^{\mathrm{c}}$ & $1 / 517$ & 0.2 \\
\hline PENTHIFRA PLUS & Placebo only & $3 / 208$ & $1.4^{\mathrm{d}}$ & $77 / 220$ & 35.0 & $8 / 327$ & 2.4 & $2 / 329$ & 0.6 \\
\hline \multicolumn{10}{|l|}{ Meta-analysis } \\
\hline Turpie et al 2002a & NA & $182 / 2682$ & $6.8^{d}$ & $371 / 2703$ & 13.7 & $96 / 3616$ & $2.7^{f}$ & $63 / 3621$ & 1.7 \\
\hline
\end{tabular}

Abbreviations: VTE, venous thromboembolism; od, once daily; bid, twice daily.

${ }^{a}$ Enoxaparin was commenced 12 hours before surgery with second injection given 12-24 hours after surgery.

${ }^{\mathrm{b}}$ Enoxaparin was commenced $12-24$ hours after surgery.

${ }^{c} \mathrm{p}<0.0001$

${ }^{d} p<0.001$

${ }^{\mathrm{e}} \mathrm{p}=0.006$

${ }^{f} p=0.008$ 
dose of $2.5 \mathrm{mg}$ subcutaneously daily commencing $6 \pm 2$ hours postoperatively, although in the PENTHIFRA study a dose was given $12 \pm 2$ hours prior to surgery if surgery was delayed $24-48$ hours after admission. The enoxaparin regime used for comparison differed among trials (Turpie et al 2003) (Table 1), with both treatments given for 5-10 days postoperatively. The primary efficacy end point of the trials was VTE, which included: (1) asymptomatic DVT demonstrated by mandatory ascending bilateral contrast venography of the legs performed on day 11 or within 48 hours of the last dose of trial drug; and (2) symptomatic DVT or PE confirmed by objective testing within 48 hours of the last dose of trial drug. The primary safety end point was major bleeding up to day 11 , defined as fatal bleeding, bleeding that was intracranial, intraspinal, into a critical organ, that required reoperation, or that did not meet the preceding criteria but was associated with a bleeding index of greater than 2 (the bleeding index was calculated as the number of units of packed cells or whole blood transfused plus prebleeding-postbleeding hemoglobin in $\mathrm{g} / \mathrm{dL}$ ) (Turpie et al 2003).

The results of the trials are presented in Table 1. A metaanalysis of these studies that included a total of 7344 subjects showed a $55.2 \%(\mathrm{p}<0.001,95 \%$ confidence interval (CI) 45.8-63.1) common odds reduction in the incidence of VTE in favor of fondaparinux (Turpie et al 2002b). Although the majority of these events were asymptomatic distal DVT detected by venography, many of which are clinically irrelevant, these are widely accepted as an appropriate surrogate for clinically important outcomes (Turpie et al 2003). As fondaparinux was initiated sooner than enoxaparin postoperatively, it is unclear if the superior efficacy is a result of the drug or timing of the first postoperative dose (Hirsh et al 2005). Major bleeding occurred more frequently in the patient group receiving fondaparinux $(p=0.008)$, although this was largely due to events with a bleeding index of 2 or more, rather than clinically significant bleeding. A post hoc analysis was performed and revealed a statistically significant relationship between timing of fondaparinux dose and bleeding, while no such relationship was seen for efficacy; patients who received their first dose of fondaparinux greater than 6 hours after surgery had a similar rate of major bleeding to those receiving enoxaparin (Turpie et al 2002b).

A single phase III trial has examined extended prophylaxis with fondaparinux in patients undergoing hip fracture surgery (Eriksson and Lassen 2003). All patients received an initial 7 days of treatment with fondaparinux and then were randomized to a further 3 weeks of fondaparinux or placebo, with venography performed at the end of study drug administration. Fondaparinux decreased the rate of DVT from $35 \%$ to $1.4 \%(\mathrm{p}<0.001)$, with symptomatic events decreasing from $2.7 \%$ to $0.3 \%$ $(p=0.02)$. A small nonsignificant increase in major bleeding was seen. This trial has led to approval of fondaparinux for extended prophylaxis following surgery for hip fracture. The results of trials of fondaparinux in general medical and surgical patients have been reported in abstract form, with fondaparinux appearing equivalent to dalteparin for VTE prophylaxis following abdominal surgery, and not surprisingly, superior to placebo at preventing VTE in acutely ill medical patients (Hirsh et al 2005).

\section{Treatment trials}

Two trials have evaluated fondaparinux for initial treatment of VTE (Buller et al 2003, 2004). The Matisse-DVT trial compared daily subcutaneous fondaparinux $(5.0 \mathrm{mg}$ daily if $<50 \mathrm{~kg}, 7.5 \mathrm{mg}$ daily if $50-100 \mathrm{~kg}, 10 \mathrm{mg}$ daily if $>100 \mathrm{~kg}$ ) with enoxaparin $1 \mathrm{mg} / \mathrm{kg}$ twice daily for the initial treatment of symptomatic proximal DVT. Patients in both study arms received the study drug for at least 5 days and until vitamin $\mathrm{K}$ antagonist therapy resulted in an International Normalized Ratio (INR) of $\geq 2$ for two consecutive days. Treatment with a vitamin $\mathrm{K}$ antagonist was continued for 3 months. The fondaparinux regime had been determined by a previous dose-finding study (Rembrandt 2000). After 3 months, symptomatic recurrence occurred in 43/1098 (3.9\%) and $45 / 1107$ (4.1\%) in the fondaparinux and enoxaparin groups, respectively $(95 \% \mathrm{CI}$ of the absolute difference of $0.2 \%$, 1.8 to $-1.5 \%$ ), with low and similar rates of major bleeding in both groups. Fondaparinux was judged to be non-inferior to enoxaparin with regards to both efficacy and safety.

In the Matisse-PE trial (Buller et al 2003), patients with objectively diagnosed symptomatic PE were randomized to initial treatment with either fondaparinux $(5.0,7.5$, or $10 \mathrm{mg}$ according to weight) by daily subcutaneous injection or a continuous intravenous infusion of UFH (adjusted to maintain an aPTT at 1.5-2.5 times control). Both were continued for at least 5 days and were overlapped with a vitamin $\mathrm{K}$ antagonist for at least 5 days and until the INR was $\geq 2$ on 2 consecutive days. Recurrent VTE developed during the 3-month study period in 42/1103 (3.8\%) and $56 / 1110(5.0 \%)$ of patients receiving fondaparinux and $\mathrm{UFH}$, respectively (absolute difference of $-1.2 \%, 95 \% \mathrm{CI}$ -3.0 to 0.5 ). Again, the rates of major bleeding were low and not significantly different between treatment arms. 
Based on these results, fondaparinux appears to be as effective and safe as UFH for treatment of PE.

\section{Comparison of fondaparinux to conventional anticoagulants}

Fondaparinux appears to be as effective as LMWH for the initial treatment of DVT, as effective as UFH for treatment of PE, and more effective than LMWH for prevention of VTE following orthopedic surgery. The decreased bleeding rate seen in animal studies has not been reflected in clinical studies, with the rate of significant bleeding comparable to that with conventional antithrombotic agents, although it is worth noting that five fatal bleeding episodes occurred in patients randomized to fondaparinux in the Matisse-DVT trial as opposed to none in the enoxaparin arm (Buller et al 2004). Like LMWH, it does not require laboratory monitoring, and has the additional benefit of being less dosedependent on patient size, although dose was adjusted for individuals at the extremes of body weight in both the Matisse-DVT and Matisse-PE trials. Fondaparinux does not cross react with sera from patients with HIT, and clinical HIT has not yet been associated with its use (Bauer 2003). Trials to date have excluded pregnant subjects and patients with renal failure, and at present fondaparinux should not be used in these patients groups. Unlike UFH, the anticoagulant effect of fondaparinux is not reversed by protamine sulfate (Hirsh et al 2005). Recombinant factor VIIa (rFVIIa) has been shown to attenuate the antithrombotic effect of fondaparinux in vitro and ex vivo (Bijsterveld et al 2002; Gerotziafas et al 2004b); however, its efficacy in bleeding patients is unproven, and the current expense of the drug is prohibitive. The decision to use fondaparinux for either initial treatment of VTE or prophylaxis will probably be influenced by the cost of the drug in comparison to traditional agents in most healthcare settings, although analyses using both UK and USA based models have found it to be cost-effective for prophylaxis post major orthopedic surgery.

\section{Idraparinux}

Idraparinux is an O-methylated, O-sulfated synthetic analogue of the pentasaccharide molecule, with the chemical changes resulting in a 30-fold increase in affinity for AT in comparison to fondaparinux. As a result, the half-life of idraparinux is 130 hours, making once weekly dosing feasible. Like fondaparinux, idraparinux demonstrates isolated dose-dependent antifactor Xa activity that correlates directly with the ability of the drug to inhibit thrombin generation in animal studies. Idraparinux was shown to be an effective antithrombotic agent in animal models of venous thrombosis. Due to the prolonged anticoagulant effect of the drug, an effective reversal agent would be highly desirable, particularly in bleeding patients or those who require surgery or other invasive procedures. rFVIIa has been shown to partially reverse the effect of the drug in vitro (Bijsterveld et al 2004) although evidence of clinical utility is lacking, and given the difference in half-lives, repeated dosing of rFVIIa is likely to be required.

A phase II trial reported that a dose of idraparinux $2.5 \mathrm{mg}$ weekly was as effective as warfarin for the treatment of proximal DVT, with patients receiving idraparinux having a lower rate of bleeding (The PERSIST investigators 2004). Both groups initially received enoxaparin. Whilst higher doses of idraparinux showed similar efficacy, a dose response for bleeding was seen. Therefore the dose of $2.5 \mathrm{mg}$ weekly was chosen for the ongoing van Gogh DVT and PE phase III trials.

\section{Direct $\mathrm{Xa}$ inhibitors}

Novel anticoagulant drugs that bind directly to factor Xa, inhibiting its procoagulant activity, are in the early stages of clinical development. Razaxaban (DPC 906), an orally bioavailable, nonpeptidic synthetic factor $\mathrm{Xa}$ inhibitor, at a dose of $25 \mathrm{mg} 12$ hourly appeared to be at least as effective and safe as enoxaparin for VTE prophylaxis following knee replacement surgery (Lassen et al 2003). A similar agent DX-9065a has undergone trials in coronary artery disease but not VTE (Hirsh et al 2005).

\section{Direct thrombin inhibitors}

\section{Ximelagatran}

Ximelagatran (Exanta ${ }^{\mathrm{TM}}$ ) is a new oral prodrug of melagatran, a synthetic direct thrombin inhibitor. Due to the minimal need for blood monitoring and its oral formulation, it has the potential to replace warfarin as the drug of choice for long-term anticoagulation. Results from phase III trials of Ximelagatran for various clinical indications have recently become available.

\section{Mechanism of action}

Melagatran is a dipeptide molecule that binds reversibly to the active site of thrombin, resulting in potent, AT independent, competitive inhibition of thrombin activity (Weitz and Crowther 2002; Gustafsson and Elg 2003). 
Melagatran is not orally absorbed, and therefore a lipophilic derivative, ximelagatran, was developed (Gustafsson and Elg 2003). Ximelagatran is rapidly converted to its active form, via two intermediate metabolites, within hours of oral administration (Weitz and Crowther 2002).

Unlike the heparin/AT complex, melagatran has been shown to inhibit both fluid-phase thrombin and thrombin bound to fibrin clot, a property that theoretically might result in more effective antithrombotic activity (Weitz and Crowther 2002; Klement et al 2003). Melagatran has been shown not only to inhibit thrombin activity, but also tissue factor initiated thrombin generation in a dose-dependent manner (Bostrom et al 2003, 2004). The antithrombotic efficacy of melagatran has been demonstrated in animal models of venous thrombosis (Eriksson, Carlsson, et al 1997; Weitz and Crowther 2002). Melagatran has a shallower dose-response curve than warfarin, with a 10-fold increase in dose of melagatran producing the same increase in antithrombotic activity as a doubling of the dose of warfarin (Elg et al 1999). As melagatran at therapeutic doses only marginally increases bleeding time in animal models, in comparison to significant changes seen with equivalent doses of warfarin and UFH, it appears to have a wider therapeutic window than conventional anticoagulants (Elg et al 1999; Klement et al 2003).

\section{Pharmacological considerations}

Ximelagatran demonstrates $20 \%$ oral bioavailability that is minimally affected by food intake, with peak plasma melagatran concentrations observed 1.5-2 hours after oral administration (Gustafsson and Elg 2003). After oral administration of ximelagatran, the plasma half-life of melagatran is approximately 3 hours, resulting in a need for twice daily dosing. As drug elimination is predominantly renal, the half-life is prolonged in individuals with reduced creatinine clearance (Gustafsson and Elg 2003). Minimal inter-individual variability is seen in the pharmacokinetics of ximelagatran in healthy volunteers, with the coefficient of variation in plasma melagatran levels being $20 \%$ after oral administration of ximelagatran (Gustafsson and Elg 2003). Peak plasma concentrations and AUC were linearly related to dose in both healthy volunteers (Gustafsson et al 2001) and patients undergoing major surgery (Eriksson, Arfwidsson, et al 2002). Obesity, ethnicity, and drugs inhibiting the cytochrome P450 isoenzyme activity do not influence ximelagatran pharmacokinetics (Gustafsson and Elg 2003).

\section{Effect on laboratory coagulation parameters}

The reproducible pharmacokinetic profile of ximelagatran suggests that routine laboratory monitoring during treatment is not required, a presumption that has been supported by the results of subsequent trials using fixed dose therapy. However, estimation of anticoagulant activity may still be required on occasions. In platelet poor plasma from volunteers, melagatran doubled thrombin, prothrombin, and aPTT clotting times at concentrations of $0.010,2.2$, and $0.59 \mu \mathrm{mol} / \mathrm{L}$, respectively. In patients undergoing orthopedic surgery or being treated for DVT or PE, melagatran plasma levels show a nonlinear correlation with prolongation of the aPTT, with doubling of aPTT seen at a plasma concentration of $0.6 \mu \mathrm{mol} / \mathrm{L}$ (Eriksson, Arfwidsson, et al 2002; Wahlander et al 2002; Gustafsson and Elg 2003). At the mean maximum plasma concentration of between $0.1-0.3 \mu \mathrm{mol} / \mathrm{L}$ obtained with prophylactic treatment, the aPPT was prolonged approximately 1.5 -fold (Eriksson, Arfwidsson, et al 2002)

\section{Clinical trials}

Prophylaxis trials

There are two groups of trials of ximelagatran for VTE prophylaxis following major orthopedic surgery due to the different practices of preoperative initiation of anticoagulant therapy in Europe, and postoperative commencement in North America. The two groups of trials will be discussed separately.

Trials performed in Europe studied the use of subcutaneous melagatran followed by oral ximelagatran for orthopedic prophylaxis, with melagatran normally commenced preoperatively. A range of doses of melagatran (1-4 mg bid (twice daily)) commencing preoperatively, followed by ximelagatran (6-24 $\mathrm{mg}$ bid) were shown to have acceptable safety in an initial phase II study (Eriksson, Arfwidsson, et al 2002). A larger phase II study, METHRO II, and phase III studies, METHRO III and EXPRESS, were then performed (Eriksson, Bergqvist, et al 2002; Eriksson et al 2003a, 2003b). The primary efficacy end point in these trials was the rate of total VTE including: (1) asymptomatic DVT demonstrated by mandatory bilateral venography of the legs 7-12 days after surgery; and (2) symptomatic DVT or PE confirmed by objective testing, with some trials also including unexplained death (Eriksson et al 2003a, 2003b). Severe bleeding, defined as bleeding involving a critical site (intracranial, intraocular, intraspinal, or retroperitoneal) or excessive bleeding as determined by an investigator, was 
Table 2 Prophylactic trials of melagatran (Mel)/ximelagatran (XM) in major orthopedic surgery

\begin{tabular}{|c|c|c|c|c|c|c|c|c|}
\hline \multirow[b]{2}{*}{ Trial } & \multirow[b]{2}{*}{ Treatment regime } & \multicolumn{2}{|c|}{ Total VTE } & \multicolumn{2}{|c|}{ Major VTE } & \multicolumn{2}{|c|}{ Severe bleeding } & \multirow{2}{*}{$\begin{array}{r}\text { Mean blood } \\
\text { loss (mL) }\end{array}$} \\
\hline & & $\mathbf{n}$ & $\%$ & $\mathbf{n}$ & $\%$ & $\mathbf{n}$ & $\%$ & \\
\hline \multicolumn{9}{|l|}{ European trials } \\
\hline \multirow[t]{2}{*}{ METHRO II } & Mel $3 \mathrm{mg}$ bid then XM $24 \mathrm{mg}$ bid $^{\mathrm{a}}$ & $43 / 285$ & $15.1^{\mathrm{c}}$ & $7 / 285$ & 2.5 & $18 / 360$ & 5.0 & 1331 \\
\hline & DAL $5000 \mathrm{IU}$ od & $87 / 308$ & 28.2 & $20 / 308$ & 6.5 & $9 / 381$ & 2.4 & 1165 \\
\hline \multirow[t]{2}{*}{ METHRO III } & Mel $3 \mathrm{mg}$ bid then XM $24 \mathrm{mg}$ bid $^{\mathrm{b}}$ & $355 / 1146$ & 31.0 & $65 / 1144$ & 5.7 & $20 / 1399$ & 1.4 & 1115 \\
\hline & Enoxaparin $40 \mathrm{mg}$ od & $306 / 1122$ & 27.3 & $69 / 1113$ & 6.2 & $23 / 1389$ & 1.7 & 1100 \\
\hline \multirow[t]{3}{*}{ EXPRESS } & Mel $2 \mathrm{mg}$ pre-op, $3 \mathrm{mg}$ post-op then & & & & & & & \\
\hline & XM $24 \mathrm{mg}$ bid $^{\mathrm{a}}$ & $231 / 1141$ & $20.3^{d}$ & $26 / 1138$ & 2.3 & $46 / 1378$ & $3.3^{\mathrm{e}}$ & 1015 \\
\hline & Enoxaparin $40 \mathrm{mg}$ od & $315 / 1184$ & 26.6 & $74 / 1178$ & 6.3 & $16 / 1387$ & 1.2 & 913 \\
\hline \multicolumn{9}{|l|}{ North American trials } \\
\hline \multirow[t]{2}{*}{ Francis et al 2002} & XM $24 \mathrm{mg}$ bid & $53 / 276$ & 19.2 & $9 / 274$ & 3.3 & $6 / 345$ & 1.7 & 773 \\
\hline & WAR (Target INR I.8-3.0) & $67 / 261$ & 25.7 & $13 / 258$ & 5.0 & $3 / 330$ & 0.9 & 741 \\
\hline \multirow[t]{3}{*}{ EXULT A } & XM $24 \mathrm{mg}$ bid & $|53 / 6| 4$ & 24.9 & $15 / 606$ & 2.5 & $6 / 757$ & 0.8 & 846 \\
\hline & XM $36 \mathrm{mg}$ bid & $128 / 629$ & $20.3^{f}$ & $17 / 629$ & 2.7 & $6 / 769$ & 0.8 & 840 \\
\hline & WAR (Target INR I.8-3.0) & $168 / 608$ & 27.6 & $25 / 603$ & 4.1 & $5 / 759$ & 0.7 & 861 \\
\hline \multirow[t]{2}{*}{ EXULT B } & XM $36 \mathrm{mg}$ bid & $221 / 982$ & $22.5^{g}$ & $38 / 982$ & 3.9 & $115 / 115 \mid$ & 1.0 & - \\
\hline & WAR (Target INR I.8-3.0) & $308 / 967$ & 31.9 & $40 / 967$ & 4.1 & $46 / 1148$ & 0.4 & - \\
\hline \multicolumn{9}{|l|}{ Colwell, Berkowitz, } \\
\hline \multirow[t]{2}{*}{ Davidson, et al 2003} & XM $24 \mathrm{mg}$ bid & $62 / 782$ & $7.9^{\mathrm{h}}$ & $28 / 782$ & 3.6 & $7 / 906$ & 0.8 & 964 \\
\hline & Enoxaparin $30 \mathrm{mg}$ bid & $36 / 775$ & 4.6 & $9 / 774$ & 1.2 & $8 / 910$ & 0.9 & 958 \\
\hline
\end{tabular}

NOTE: Dashes indicate data not available.

Abbreviations: Mel, melagatran; XM, ximelagatran; DAL, dalteparin; WAR, warfarin; VTE, venous thromboembolism; bid, twice a day; od, once daily; INR, International Normalized Ratio.

a Melagatran dose commenced immediately before surgery.

b Melagatran commenced 4-12 hours postoperatively.

${ }^{c} p=0.0001$

${ }^{d} p<0.0004$

${ }^{\mathrm{e}} \mathrm{P}=0.0002$

${ }^{f} p=0.003$

${ }^{g} p<0.001$

${ }^{h} p=0.009$

the primary safety end point. EXPRESS also included bleeding not from the operation wound that required $\geq 2$ unit transfusion of blood and fatal bleeding (Eriksson et al 2003b).

Table 2 summarizes the results of these trials. All trials involved patients undergoing THR and TKR, with prophylaxis being given for $8-11$ days postoperatively until mandatory venography. A melagatran/ximelagatran dosedependent decrease in VTE was shown in METHRO II. The regime of melagatran $3 \mathrm{mg}$ bid commenced immediately before surgery and continued for 1-3 days postoperatively until oral therapy with ximelagatran $24 \mathrm{mg}$ bid could be commenced was found to have maximum efficacy. This regime was significantly more effective at preventing VTE than dalteparin started preoperatively, with a nonsignificant increase in bleeding seen (Eriksson, Bergqvist, et al 2002). In an attempt to limit the risk of bleeding, METHRO III utilized the same drug doses, but started melagatran 4-12 hours postoperatively. Whilst a similar bleeding rate to enoxaparin was seen, the rate of VTE in subjects given ximelagatran was the same as patients receiving enoxaparin
(Eriksson et al 2003a). It appeared that the timing of starting melagatran, ie, pre- or postoperatively, influenced efficacy. In an attempt to maximize the benefit to risk ratio, the EXPRESS trial used a reduced dose of melagatran of $2 \mathrm{mg}$ immediately prior to surgery, followed by $3 \mathrm{mg}$ on the evening of surgery, switching to oral ximelagatran $24 \mathrm{mg}$ bid the next day (Eriksson et al 2003b). This protocol was associated with a significant reduction in total and major (proximal DVT and/or PE) VTE in comparison to enoxaparin commenced preoperatively, with no increase in bleeding seen in patients undergoing TKR, but an increased rate of noncritical bleeding in patients undergoing THR receiving melagatran/ximelagatran. In addition, one case of fatal intraoperative hemorrhage, a rare event during orthopedic surgery, occurred in the ximelagatran group following iatrogenic injury to the iliac and femoral vessels.

Trials evaluating ximelagatran for orthopedic prophylaxis in North America used a twice-daily oral regime commencing 12-24 hours postoperatively or the next morning after surgery. An initial dose-ranging study evaluating $8-24 \mathrm{mg}$ twice daily found the highest dose to 
be the most effective in patients undergoing TKR, with ximelagatran $24 \mathrm{mg}$ bid showing a nonsignificant decrease in VTE in comparison to postoperative enoxaparin $30 \mathrm{mg}$ 12 hourly, with no difference seen in bleeding rates (Heit et al 2001). Further phase III studies were then performed and utilized either this dose or $36 \mathrm{mg}$ bid. The primary efficacy end point in these trials was the same as the above studies, with death also included in the primary efficacy end point in the EXULT A and B trials (Colwell, Berkowitz, Comp, et al 2003; Francis, Berkowitz, et al 2003). The major safety end point was major bleeding, defined as fatal bleeding, critical bleeding (as defined above), requiring reoperation, or bleeding associated with a bleeding index of $\geq 2$ (as previously defined).

The trials are summarized in Table 2. Treatment was given for 7-12 days in all studies, and all were double-blind, randomized controlled trials. Three trials compared ximelagatran with warfarin for VTE prophylaxis in patients undergoing TKR. Francis et al (2002) reported a significantly lower incidence of total VTE and a trend towards less major VTE in patients receiving ximelagatran $24 \mathrm{mg}$ bid, compared with patients receiving warfarin prophylaxis commencing at a minimum dose of $5 \mathrm{mg}$ on the evening of surgery, then titrated to an INR of 1.8-3.0. No significant increase in bleeding was seen. The efficacy of a higher dose of ximelagatran, $36 \mathrm{mg}$ bid, was assessed in EXULT A and was found to be more effective (absolute risk reduction of $7.3 \%, 95 \%$ CI $2.5-12.0$ ) than warfarin for preventing VTE, with no excess of bleeding seen (Francis, Berkowitz, et al 2003). The improved efficacy of ximelagatran $36 \mathrm{mg}$ bid in comparison to warfarin was confirmed by EXULT B, reported recently in abstract form (Colwell, Berkowitz, Comp, et al 2003).

Results from the phase II study suggested that ximelagatran $24 \mathrm{mg}$ bid commencing postoperatively might be effective for prevention of VTE in patients undergoing THR (Heit et al 2001). However, this dose of ximelagatran was shown to have inferior efficacy in comparison to enoxaparin $30 \mathrm{mg} 12$ hourly in patients undergoing THR, with the rate of major bleeding being similar (Colwell, Berkowitz, Davidson, et al 2003).

\section{Treatment of VTE}

THRIVE I was a randomized dose-finding study evaluating the efficacy and tolerability of ximelagatran for the initial treatment of DVT, in comparison to dalteparin followed by warfarin (Eriksson, Wahlander, et al 2003). Patients were randomized to receive ximelagatran $(24,36,48$, or $60 \mathrm{mg}$ twice daily), or dalteparin $200 \mathrm{U} \mathrm{kg}^{-1}$ subcutaneously once daily and warfarin adjusted to achieve an INR of between 2 and 3. Efficacy was determined by comparing paired venograms obtained prior to treatment commencing and at the end of the two week treatment period. Regression of thrombus was seen in $69 \%$ of patients treated with ximelagatran and $69 \%$ of patients treated with dalteparin and warfarin, with no significant difference in response rate seen among treatment groups. Ximelagatran was well tolerated and appeared to be an effective agent for treatment of VTE.

The clinical efficacy of ximelagatran in extended secondary prevention of VTE was then assessed in THRIVE III, a multicentre, randomized controlled trial (Schulman et al 2003). After completion of six months of anticoagulant therapy for objectively confirmed DVT or PE, patients were randomized to receive ximelagatran 24 bid or placebo twice daily for a period of 18 months. The primary efficacy end point was symptomatic, objectively-confirmed recurrent VTE occurring during the study period. As compared with placebo, ximelagatran significantly reduced the rate of recurrent VTE $(p<0.001)$, with the estimated cumulative risk of recurrence after 18 months of treatment being $2.8 \%$ in the ximelagatran group and $12.6 \%$ in the placebo group. The hazard ratio for the ximelagatran group for major bleeding in comparison to placebo was $1.16(95 \% \mathrm{CI}$ 0.35-3.80). Asymptomatic elevation of alanine aminotransferase levels to more than three times the upper limit of normal was more frequent in individuals receiving ximelagatran than placebo, with the estimated cumulative risk of such an elevation by 18 months being $6.4 \%$ in patients receiving ximelagatran, compared with $1.2 \%$ in those receiving placebo. At the last observation during the study, liver enzyme levels had normalized in all but 4 of 37 affected patients (two of whom had known hepatitis predating commencement of ximelagatran). The time to normalization was similar regardless of whether ximelagatran was continued (median time 84 days), or discontinued (median time 128 days).

The results of trials of ximelagatran for the initial treatment of acute DVT with or without PE were recently presented in abstract form (Francis, Ginsberg, et al 2003). In a randomized, double-blind, double-dummy trial, patients with acute symptomatic DVT were randomized to receive either ximelagatran $36 \mathrm{mg}$ bid for six months, or subcutaneous enoxaparin $1 \mathrm{mg} / \mathrm{kg}$ bid and warfarin, with enoxaparin given for a minimum of 5 days and until the INR was $\geq 2$ for at least for 48 hours, and warfarin (target INR 2.0-3.0) continued for six months. Ximelagatran was 
shown to be non-inferior to enoxaparin/warfarin for prevention of recurrent VTE, with a trend towards less major bleeding in the ximelagatran group. The incidence of elevation of alanine aminotransferase levels above three times the upper limit of normal was $9.6 \%$ in patients receiving ximelagatran, versus $2.0 \%$ in those treated with enoxaparin/warfarin. Follow-up data on subsequent normalization or otherwise of liver enzyme levels in these individuals has not as yet been published.

\section{Comparison of ximelagatran to conventional anticoagulants}

Ximelagatran appears to be an effective agent for both prevention and treatment of VTE. At doses studied, when used alone as an oral agent it has superior efficacy to warfarin for preventing VTE post TKR, but inferior efficacy when used for VTE prevention following THR. The risk of bleeding appears equivalent, and it has the additional benefits over warfarin of rapid onset of action, lack of interaction with food and other drugs, and predictable pharmacokinetics, removing the need for drug monitoring. Although, unlike warfarin, a clinically tested antidote is not yet available, the shorter half-life of ximelagatran may minimize the requirement for reversal of its anticoagulant effect. Activated prothrombin complex concentrates have been shown to reverse melagatran induced prolongation of bleeding times in animal models, and may prove to have clinical utility.

When compared with standard LMWH regimes, subcutaneous melagatran commenced preoperatively followed by ximelagatran appeared to have improved efficacy in patients undergoing either THR or TKR surgery, although bleeding was increased in the THR subjects. The decision to choose melagatran/ximelagatran over LMWH may come down to individual assessment of bleeding and VTE risk. The potential risk of HIT associated with LMWH is avoided by melagatran. Ximelagatran may prove to be an ideal agent for extended prophylaxis following orthopedic surgery, given its oral formulation and lack of need for monitoring.

Ximelagatran has also shown efficacy in the primary treatment of acute VTE, and in secondary prophylaxis following an acute event. The advantages of the drug over warfarin, as listed above, may lead to it becoming the agent of choice for these indications. However, concern currently exists with regards to the development of elevated transaminase levels to a level of above three times normal in $5 \%-10 \%$ of individuals receiving ximelagatran for greater than one month (Francis, Ginsberg, et al 2003; Olsson 2003; Schulman et al 2003) The rate of elevation of liver aminotransferase levels was higher in individuals receiving the higher dose of ximelagatran in the THRIVE treatment (36 mg bid) trial, than those individuals in THRIVE III (24 mg bid), suggesting a possible dose relationship. Against this, the rate of elevation of alanine aminotransferase levels to above three times normal in SPORTIF III (Olsson 2003) a trial in which patients with atrial fibrillation received ximelagatran $36 \mathrm{mg}$ bid, was $6 \%$, a similar rate to that seen with the lower dose in THRIVE III. Ongoing trials require discontinuation of ximelagatran in participants who develop marked or persistent elevations of transaminases; this side effect may result in the need for routine monitoring of liver function tests if ximelagatran is continued for more than 30 days, negating some of the benefit of the lack of need for therapeutic monitoring. Concerns with regards to liver toxicity contributed to the Food and Drug Administration (FDA) decision to recently reject an initial application for approval of ximelagatran for prophylactic and treatment indications (Anonymous 2004).

\section{Other direct thrombin inhibitors}

Hirudin, bivalirudin, and argatroban are all direct thrombin inhibitors which unlike ximelagatran, require parenteral administration (Weitz and Crowther 2002). Hirudin was originally isolated from the medicinal leech and is the prototypical direct thrombin inhibitor. It binds bivalently to the active site and exosite 1 of thrombin in an essentially irreversible manner (Bates and Weitz 2003). A recombinant desulfated form of hirudin, lepirudin, is commercially available. Bivalirudin is a 20 amino acid synthetic molecule, which like hirudin, binds thrombin bivalently (Weitz and Crowther 2002). Once bound to thrombin, bivalirudin undergoes cleavage leading to dissociation of its aminoterminal from the active site of thrombin, with the carboxyterminal remaining only weakly bound to exosite 1 (Witting et al 1992). This causes bivalirudin inhibition of thrombin to be competitive and reversible, which, combined with a shorter half-life ( 25 minutes compared with 60 minutes after intravenous infusion), may result in bivalirudin having improved safety compared with hirudin (Bates and Weitz 2003). Argatroban is a small synthetic, arginine derivative that binds reversibly to the active site of thrombin, resulting in competitive inhibition of thrombin activity. The plasma half-life of argatroban is 45-60 minutes when given 
intravenously, with metabolism being hepatic unlike lepirudin bivalirudin which undergoes renal clearance (Weitz and Crowther 2002).

Lepirudin and argatroban have received FDA approval for treatment of HIT and have been shown to be effective in comparison to historical controls in reducing morbidity and mortality, supporting the central role of thrombin in the pathogenesis of this condition (Warkentin 2003). There is also anecdotal evidence supporting the use of bivalirudin for this condition. For details with regards to treatment regimes, readers are referred to a recent review (Warkentin 2003). Despite phase III trial data showing recombinant hirudin to have superior efficacy and similar safety to UFH and LMWH for prevention of VTE following hip surgery (Eriksson, Ekman, et al 1997; Eriksson, Wille-Jorgensen, et al 1997), and promising phase II data for bivalirudin for the same indication (Ginsberg et al 1994), neither agent is currently marketed or being developed for this indication.

\section{Drugs potentiating the protein $\mathrm{C}$ anticoagulant pathway}

\section{Soluble thrombomodulin}

Normally located on endothelial cells, thrombomodulin is a transmembrane protein that forms a 1:1 complex with thrombin, with the interaction inducing a conformational change in thrombin. This results in inhibition of the ability of thrombin to cleave fibrinogen and activate FV, FXIII, and platelets, but also results in a 1000-fold increase in its efficacy as an activator of protein C (Dittman and Majerus 1990). Soluble thrombomodulin is a functionally active, truncated form of the protein that has been isolated from human blood (Dittman and Majerus 1990). A recombinant form of soluble thrombomodulin (ART-123) with a halflife of 2-3 days has been evaluated for VTE prophylaxis following hip arthroplasty in a dose-finding study (Kearon et al 2003). A regime of $0.3 \mathrm{mg} / \mathrm{kg}$ subcutaneously $2-4$ hours after surgery, followed by the same dose on day 5 , was associated with a rate of VTE of $4.3 \%$ (including events detected by mandatory venography), and an incidence of major bleeding of $1.6 \%$. A single higher dose following surgery demonstrated increased efficacy but also an increased incidence of bleeding.

\section{Conclusions and future directions}

After many years of limited therapeutic options for both initial and extended antithrombotic therapy for VTE, new anticoagulants with proven efficacy have become available to the practicing clinician, with others likely to follow in the near future. The clinical development of fondaparinux and ximelagatran is furthest advanced, with both drugs having been shown to be effective treatment for both VTE prevention and prophylaxis. Neither drug requires routine monitoring to maximize efficacy and safety, an advantage over traditional antithrombotic agents that will be embraced by both patient and clinician alike. As yet, clinical data has not consistently supported the reduced risk of bleeding seen in animal studies with many new anticoagulant drugs. Ultimately, cost considerations, both individual and institutional, will influence the degree to which these new drugs are accepted as standard care.

\section{Acknowledgments}

Dr Simon J McRae is a recipient of the WE Noonan Fellowship Award. Dr Jeffrey S Ginsberg is a recipient of a Career Investigator Award from the Heart and Stroke Foundation of Ontario and a Research Chair from the Canadian Institutes of Health Research.

\section{References}

Anonymous. 2004. Is that it, then, for blockbuster drugs? [editorial]. Lancet, 364:1100.

Barritt DW, Jordan SC. 1960. Anticoagulant drugs in the treatment of pulmonary embolism. A controlled trial. Lancet, 1:1309-12.

Bates SM, Weitz JI. 2003. Emerging anticoagulant drugs. Arterioscler Thromb Vasc Biol, 23:1491-500.

Bauer KA. 2003. New pentasaccharides for prophylaxis of deep vein thrombosis: pharmacology. Chest, 124:364S-370S

Bauer KA, Eriksson BI, Lassen MR, et al. 2001. Fondaparinux compared with enoxaparin for the prevention of venous thromboembolism after elective major knee surgery. $N$ Engl J Med, 345:1305-10.

Baugh RJ, Broze GJ Jr, Krishnaswamy S. 1998. Regulation of extrinsic pathway factor Xa formation by tissue factor pathway inhibitor. $J$ Biol Chem, 273:4378-86.

Beguin S, Choay J, Hemker HC. 1989. The action of a synthetic pentasaccharide on thrombin generation in whole plasma. Thromb Haemost, 61:397-401.

Bijsterveld NR, Moons AH, Boekholdt SM, et al. 2002. Ability of recombinant factor VIIa to reverse the anticoagulant effect of the pentasaccharide fondaparinux in healthy volunteers. Circulation, $106: 2550-4$

Bijsterveld NR, Vink R, van Aken BE, et al. 2004. Recombinant factor VIIa reverses the anticoagulant effect of the long-acting pentasaccharide idraparinux in healthy volunteers. Br J Haematol, 124:653-8.

Boneu B, Necciari J, Cariou R, et al. 1995. Pharmacokinetics and tolerance of the natural pentasaccharide (SR90107/Org31540) with high affinity to antithrombin III in man. Thromb Haemost, 74:1468-73.

Bostrom SL, Dagnelid E, Hansson GF, et al. 2004. Inhibition of thrombininduced feedback activation of factor $\mathrm{V}$ : a potential pathway for inhibition of thrombin generation by melagatran. Blood Coagul Fibrinolysis, 15:25-30. 
Bostrom SL, Hansson GF, Kjaer M, et al. 2003. Effects of melagatran, the active form of the oral direct thrombin inhibitor ximelagatran, and dalteparin on the endogenous thrombin potential in venous blood from healthy male subjects. Blood Coagul Fibrinolysis, 14:457-62.

Brufatto N, Ward A, Nesheim ME. 2003. Factor Xa is highly protected from antithrombin-fondaparinux and antithrombin-enoxaparin when incorporated into the prothrombinase complex. J Thromb Haemost, 1:1258-63.

Buller HR, Davidson BL, Decousus H, et al. 2003. Subcutaneous fondaparinux versus intravenous unfractionated heparin in the initial treatment of pulmonary embolism. N Engl J Med, 349:1695-702.

Buller HR, Davidson BL, Decousus H, et al. 2004. Fondaparinux or enoxaparin for the initial treatment of symptomatic deep venous thrombosis: a randomized trial. Ann Intern Med, 140:867-73.

Carrie D, Caranobe C, Saivin S, et al. 1994. Pharmacokinetic and antithrombotic properties of two pentasaccharides with high affinity to antithrombin III in the rabbit: comparison with CY216. Blood, $84: 2571-7$

Choay J, Lormeau JC, Petitou M, et al. 1981. Structural studies on a biologically active hexasaccharide obtained from heparin. Ann NY Acad Sci, 370:644-9.

Colwell CW, Berkowitz SD, Comp PC, et al. 2003. Randomized, doubleblind comparison of ximelagatran, an oral direct thrombin inhibitor, and warfarin to prevent venous thromboembolism (VTE) after total knee replacement (TKR): EXULT B. Blood, 102(Suppl):abstract nr 39.

Colwell CW Jr, Berkowitz SD, Davidson BL, et al. 2003. Comparison of ximelagatran, an oral direct thrombin inhibitor, with enoxaparin for the prevention of venous thromboembolism following total hip replacement. A randomized, double-blind study. J Thromb Haemost, 1:2119-30.

Davie EW. 1995. Biochemical and molecular aspects of the coagulation cascade. Thromb Haemost, 74:1-6.

Depasse F, Gerotziafas GT, Busson J, et al. 2004. Assessment of three chromogenic and one clotting assays for the measurement of synthetic pentasaccharide fondaparinux (Arixtra) anti-Xa activity. $J$ Thromb Haemost, 2:346-8.

Dittman WA, Majerus PW. 1990. Structure and function of thrombomodulin: a natural anticoagulant. Blood, 75:329-36.

Donat F, Duret JP, Santoni A, et al. 2002. The pharmacokinetics of fondaparinux sodium in healthy volunteers. Clin Pharmacokinet, 41(Supp1 2):1-9.

Elg M, Gustafsson D, Carlsson S. 1999. Antithrombotic effects and bleeding time of thrombin inhibitors and warfarin in the rat. Thromb Res, 94:187-97.

Eriksson BI, Agnelli G, Cohen AT, et al. 2003a. Direct thrombin inhibitor melagatran followed by oral ximelagatran in comparison with enoxaparin for prevention of venous thromboembolism after total hip or knee replacement. Thromb Haemost, 89:288-96.

Eriksson BI, Agnelli G, Cohen AT, et al. 2003b. The direct thrombin inhibitor melagatran followed by oral ximelagatran compared with enoxaparin for the prevention of venous thromboembolism after total hip or knee replacement: the EXPRESS study. J Thromb Haemost, 1:2490-6.

Eriksson BI, Arfwidsson AC, Frison L, et al. 2002. A dose-ranging study of the oral direct thrombin inhibitor, ximelagatran, and its subcutaneous form, melagatran, compared with dalteparin in the prophylaxis of thromboembolism after hip or knee replacement: METHRO I. MElagatran for THRombin inhibition in Orthopaedic surgery. Thromb Haemost, 87:231-7.

Eriksson BI, Bauer KA, Lassen MR, et al. 2001. Fondaparinux compared with enoxaparin for the prevention of venous thromboembolism after hip-fracture surgery. N Engl J Med, 345:1298-304.

Eriksson BI, Bergqvist D, Kalebo P, et al. 2002. Ximelagatran and melagatran compared with dalteparin for prevention of venous thromboembolism after total hip or knee replacement: the METHRO II randomised trial. Lancet, 360:1441-7.
Eriksson BI, Carlsson S, Halvarsson M, et al. 1997. Antithrombotic effect of two low molecular weight thrombin inhibitors and a low-molecular weight heparin in a caval vein thrombosis model in the rat. Thromb Haemost, 78:1404-7.

Eriksson BI, Ekman S, Lindbratt S, et al. 1997. Prevention of thromboembolism with use of recombinant hirudin. Results of a double-blind, multicenter trial comparing the efficacy of desirudin (Revasc) with that of unfractionated heparin in patients having a total hip replacement. J Bone Joint Surg Am, 79:326-33.

Eriksson BI, Lassen MR. 2003. Duration of prophylaxis against venous thromboembolism with fondaparinux after hip fracture surgery: a multicenter, randomized, placebo-controlled, double-blind study. Arch Intern Med, 163:1337-42.

Eriksson BI, Wille-Jorgensen P, Kalebo P, et al. 1997. A comparison of recombinant hirudin with a low-molecular-weight heparin to prevent thromboembolic complications after total hip replacement. $N$ Engl $J$ Med, 337:1329-35.

Eriksson H, Wahlander K, Gustafsson D, et al. 2003. A randomized, controlled, dose-guiding study of the oral direct thrombin inhibitor ximelagatran compared with standard therapy for the treatment of acute deep vein thrombosis: THRIVE I. J Thromb Haemost, 1:41-7.

Esmon CT. 1989. The roles of protein C and thrombomodulin in the regulation of blood coagulation. J Biol Chem, 264:4743-6.

Francis CW, Berkowitz SD, Comp PC, et al. 2003. Comparison of ximelagatran with warfarin for the prevention of venous thromboembolism after total knee replacement. $N$ Engl J Med, 349:1703-12.

Francis CW, Davidson BL, Berkowitz SD, et al. 2002. Ximelagatran versus warfarin for the prevention of venous thromboembolism after total knee arthroplasty. A randomized, double-blind trial. Ann Intern Med, 137:648-55.

Francis CW, Ginsberg JS, Berkowitz SD, et al. 2003. Efficacy and safety of the oral direct thrombin inhibitor Ximelagatran compared with current standard therapy for acute, symptomatic deep vein thrombosis, with or without pulmonary embolism: The Thrive Treatment Study. Blood, 102(Suppl):abstract nr 7.

Geerts WH, Heit JA, Clagett GP, et al. 2001. Prevention of venous thromboembolism. Chest, 119:132S-175S

Gerotziafas GT, Depasse F, Chakroun T, et al. 2004a. Comparison of the effect of fondaparinux and enoxaparin on thrombin generation during in-vitro clotting of whole blood and platelet-rich plasma. Blood Coagul Fibrinolysis, 15:149-56.

Gerotziafas GT, Depasse F, Chakroun T, et al. 2004b. Recombinant factor VIIa partially reverses the inhibitory effect of fondaparinux on thrombin generation after tissue factor activation in platelet rich plasma and whole blood. Thromb Haemost, 91:531-7.

Ginsberg JS, Nurmohamed MT, Gent M, et al. 1994. Use of Hirulog in the prevention of venous thrombosis after major hip or knee surgery. Circulation, 90:2385-9.

Gustafsson D, Elg M. 2003. The pharmacodynamics and pharmacokinetics of the oral direct thrombin inhibitor ximelagatran and its active metabolite melagatran: a mini-review. Thromb Res, 109(Supp1 1): S9-15.

Gustafsson D, Nystrom J, Carlsson S, et al. 2001. The direct thrombin inhibitor melagatran and its oral prodrug $\mathrm{H}$ 376/95: intestinal absorption properties, biochemical and pharmacodynamic effects. Thromb Res, 101:171-81.

Heit JA, Colwell CW, Francis CW, et al. 2001. Comparison of the oral direct thrombin inhibitor ximelagatran with enoxaparin as prophylaxis against venous thromboembolism after total knee replacement: a phase 2 dose-finding study. Arch Intern Med, 161:2215-21.

Herbert JM, Lormeau JC, Cariou R, et al. 1997. SR 901071/Org 31540, a novel anti-factor Xa antithrombotic agent. Cardiovacs Drug Rev, 15: $1-26$.

Hirsh J, Dalen J, Anderson DR, et al. 2001. Oral anticoagulants: mechanism of action, clinical effectiveness, and optimal therapeutic range. Chest, 119:8S-21S. 
Hirsh J, O’Donnell M, Weitz JI. 2005. New anticoagulants. Blood, 105: 453-63.

Hirsh J, Warkentin TE, Shaughnessy SG, et al. 2001. Heparin and lowmolecular-weight heparin: mechanisms of action, pharmacokinetics, dosing, monitoring, efficacy, and safety. Chest, 119:64S-94S.

Hull RD, Raskob GE, Hirsh J, et al. 1986. Continuous intravenous heparin compared with intermittent subcutaneous heparin in the initial treatment of proximal-vein thrombosis. N Engl J Med, 315:1109-14

Huntington JA, McCoy A, Belzar KJ, et al. 2000. The conformational activation of antithrombin. A 2.85-A structure of a fluorescein derivative reveals an electrostatic link between the hinge and heparin binding regions. $J$ Biol Chem, 275:15377-83.

Kearon C, Comp C, Douketis J, et al. 2003. A dose-response study of a recombinant human soluble thrombomodulin (ART-123) for prevention of venous thromboembolism after unilateral total hip replacement. $J$ Thromb Haemost, 1(Suppl 1):abstract nr OC330.

Klement P, Carlsson S, Rak J, et al. 2003. The benefit-to-risk profile of melagatran is superior to that of hirudin in a rabbit arterial thrombosis prevention and bleeding model. J Thromb Haemost, 1:587-94.

Lagerstedt CI, Olsson CG, Fagher BO, et al. 1985. Need for long-term anticoagulant treatment in symptomatic calf-vein thrombosis. Lancet, 2:515-18.

Lagrange F, Vergnes C, Brun JL, et al. 2002. Absence of placental transfer of pentasaccharide (fondaparinux, Arixtra) in the dually perfused human cotyledon in vitro. Thromb Haemost, 87:831-5.

Lassen MR, Bauer KA, Eriksson BI, et al. 2002. Postoperative fondaparinux versus preoperative enoxaparin for prevention of venous thromboembolism in elective hip-replacement surgery: a randomised double-blind comparison. Lancet, 359:1715-20.

Lassen MR, Davidson BL, Gallus A, et al. 2003. A phase II randomized, double-blind, five-arm, parallel-group, dose-response study of a new oral directly-acting factor Xa inhibitor, razaxaban, for the prevention of deep vein thrombosis in knee replacement surgery-on behalf of the razaxaban investigators. Blood, 102(Suppl):abstract nr 41.

Lee A, Agnelli G, Buller H, et al. 2001. Dose-response study of recombinant factor VIIa/tissue factor inhibitor recombinant nematode anticoagulant protein $\mathrm{c} 2$ in prevention of postoperative venous thromboembolism in patients undergoing total knee replacement. Circulation, 104: 74-8.

Lee AY, Vlasuk GP. 2003. Recombinant nematode anticoagulant protein c2 and other inhibitors targeting blood coagulation factor VIIa/tissue factor. J Intern Med, 254:313-21.

Linkins LA, Julian JA, Rischke J, et al. 2002. In vitro comparison of the effect of heparin, enoxaparin and fondaparinux on tests of coagulation. Thromb Res, 107:241-4.

Lormeau JC, Herault JP. 1993. Comparative inhibition of extrinsic and intrinsic thrombin generation by standard heparin, a low molecular weight heparin and the synthetic ATIII-binding pentasaccharide. Thromb Haemost, 69:152-6, 176.

Lormeau JC, Herault JP. 1995. The effect of the synthetic pentasaccharide SR 90107/ORG 31540 on thrombin generation ex vivo is uniquely due to ATIII-mediated neutralization of factor Xa. Thromb Haemost, $74: 1474-7$.
Mann KG, Brummel K, Butenas S. 2003. What is all that thrombin for? $J$ Thromb Haemost, 1:1504-14.

Olson ST, Bjork I, Sheffer R, et al. 1992. Role of the antithrombin-binding pentasaccharide in heparin acceleration of antithrombin-proteinase reactions. Resolution of the antithrombin conformational change contribution to heparin rate enhancement. J Biol Chem, 267: $12528-38$

Olsson SB. 2003. Stroke prevention with the oral direct thrombin inhibitor ximelagatran compared with warfarin in patients with non-valvular atrial fibrillation (SPORTIF III): randomised controlled trial. Lancet, 362:1691-8.

Schulman S, Wahlander K, Lundstrom T, et al. 2003. Secondary prevention of venous thromboembolism with the oral direct thrombin inhibitor ximelagatran. $N$ Engl J Med, 349:1713-21.

The PERSIST investigators. 2004. A novel long-acting synthetic factor Xa inhibitor (SanOrg34006) to replace warfarin for secondary prevention in deep vein thrombosis. A Phase II evaluation. $J$ Thromb Haemost, 2:47-53.

The Rembrandt Investigators. 2000. Treatment of proximal deep vein thrombosis with a novel synthetic compound (SR90107A/ORG31540) with pure anti-factor Xa activity: a phase II evaluation. Circulation, 102:2726-31.

Turpie AG, Bauer KA, Eriksson BI, et al. 2002a. Postoperative fondaparinux versus postoperative enoxaparin for prevention of venous thromboembolism after elective hip-replacement surgery: a randomised double-blind trial. Lancet, 359:1721-6.

Turpie AG, Bauer KA, Eriksson BI, et al. 2002b. Fondaparinux vs enoxaparin for the prevention of venous thromboembolism in major orthopedic surgery: a meta-analysis of 4 randomized double-blind studies. Arch Intern Med, 162:1833-40.

Turpie AG, Eriksson BI, Bauer KA, et al. 2003. New pentasaccharides for the prophylaxis of venous thromboembolism: clinical studies. Chest, 124:371S-378S

Turpie AG, Gallus AS, Hoek JA. 2001. A synthetic pentasaccharide for the prevention of deep-vein thrombosis after total hip replacement. N Engl J Med, 344:619-25.

Wahlander K, Lapidus L, Olsson CG, et al. 2002. Pharmacokinetics, pharmacodynamics and clinical effects of the oral direct thrombin inhibitor ximelagatran in acute treatment of patients with pulmonary embolism and deep vein thrombosis. Thromb Res, 107:93-9.

Walenga JM, Jeske WP, Bara L, et al. 1997. Biochemical and pharmacologic rationale for the development of a synthetic heparin pentasaccharide. Thromb Res, 86:1-36.

Warkentin TE. 2003. Heparin-induced thrombocytopenia: pathogenesis and management. Br J Haematol, 121:535-55.

Weitz JI, Crowther M. 2002. Direct thrombin inhibitors. Thromb Res, 106:V275-84.

White RH. 2003. The epidemiology of venous thromboembolism. Circulation, 107(23 Suppl 1):I4-8.

Witting JI, Bourdon P, Brezniak DV, et al. 1992. Thrombin-specific inhibition by and slow cleavage of hirulog-1. Biochem J, 283(Pt 3): $737-43$. 